\title{
INHERITANCE, OBLIGATION, AND \\ RESPONSIBILITY IN A COMMONS DILEMMA
}

by

Michael K. Porter

\begin{abstract}
A Thesis
Presented to
\end{abstract}

The Faculty of Humboldt State University

In Partial Fulfillment

Of the Requirements for the Degree

Master of Arts

In Psychology: Academic Research, Social and Environmental Psychology

August, 2007 



\begin{abstract}
Commons dilemmas occur when individuals harvest from diminishing yet renewable resources like timber or fish populations. Individuals can sustain a resource for a group by harvesting conservatively (cooperation) or they can maximize short-term personal gain at the expense of the group by harvesting heavily (defection). However, if all defect, everyone gets less than if they had cooperated because the resource will deplete faster. The effects of perceived inheritance on harvesting decisions was examined in the context of a commons dilemma simulation.

Undergraduates $(N=66)$ participated in a commons dilemma simulation using points recorded on a chalk board. Each point harvested earned participants an entry into a drawing for \$50 in cash and prizes. Before harvesting from the resource, participants estimated the percentage of their peers who would preserve and exploit the resource and indicated how obligated they felt to preserve it. For the experimental manipulation, participants were assigned to the conservative, sustainable, or exploitive conditions who learned that a previous group had grown, kept steady, or diminished the resource, respectively. A control group simply played the commons game. Following the simulation, participants indicated their sense of responsibility for the outcome of the game, and completed an environmental attitudes questionnaire.

As this is an exploratory study, several research questions are proposed for how the inheritance manipulation may affect behavior. No direct effect of inheritance was
\end{abstract}


found. However, intriguing results supporting hypotheses involving the obligation, peer expectations, responsibility, and environmental attitudes measures were found. 


\section{DEDICATION}

I dedicate my thesis to the memory of Zach Novak. You were taken too soon, but your music lives on forever. 


\section{ACKNOWLEDGEMENTS}

There are many people I would like to thank for their invaluable support and guidance during the process of completing this thesis. First and foremost, I would like to thank Dr. David Campbell, my thesis chair and advisor, who piqued my interest in the study of commons dilemmas when I returned to HSU in the fall of 2004. From our first semester of coffee-house meetings where we began to review literature, to the development of the Humboldt Environmental Attitudes Test, to conducting new, unique experiments on commons dilemmas, I have learned so much from you. Thank you for the opportunity to become involved in research in the field of environmental psychology.

Thank you to Dr. Christopher Aberson, whose classes in statistics and research methods have prepared me to begin a career in research. Thank you for statistical consultation throughout the data analysis process and for serving on my thesis committee. Thanks also for allowing me to become involved in your own research, through which I have learned so much about research in the field of social psychology.

Thank you to Dr. Gregg Gold, whose passion for social psychological research inspired me to be more creative in my own research design. Thank you for serving on my thesis committee and for introducing me to the literature on priming methodology, which helped lead to the development of the design of this thesis. Thanks also for the opportunity to develop my teaching skills in your course on the psychology of prejudice.

Thank you to Kacy Pula for your assistance in collecting and analyzing data. Thank you to Jeremy Evanston for data collection. 
Last but certainly not least, thank you to Breanne Porter for your amazing work in the designing and conducting of this study. Discussing the meaning and implications of this study with you has been truly wonderful. I could not have done it without you. Thank you. 


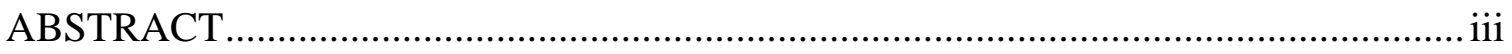

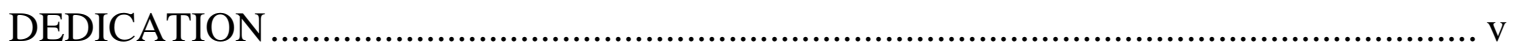

ACKNOWLEDGEMENTS …………………………............................................ vi

TABLE OF CONTENTS ........................................................................................... viii

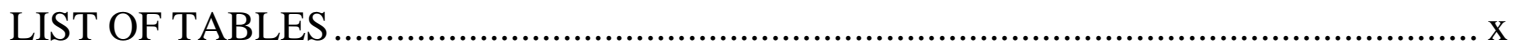

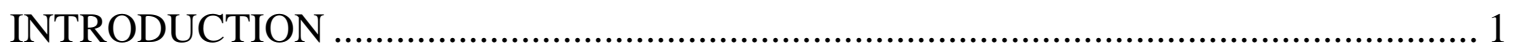

REVIEW OF THE LITERATURE ……………………......................................... 3

Environmental Attitudes and Commons Dilemmas ................................................ 4

Commons Dilemmas in the Real World ............................................................... 5

Inheritance and Behavior in the Commons........................................................... 9

Inheritance and Sense of Obligation to Preserve the Resource ................................ 9

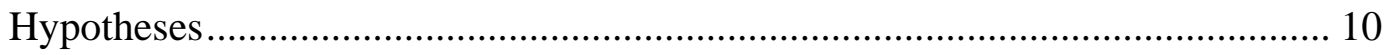

Inheritance and Participants’ Beliefs about Peers.................................................... 11

Perception of Responsibility for Commons Outcome ……………………............ 11

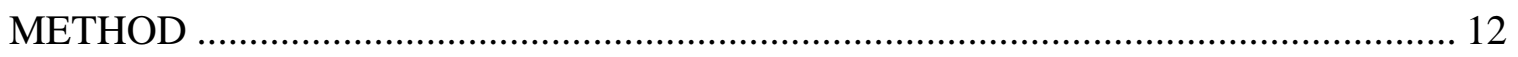

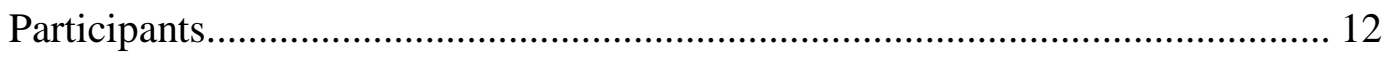

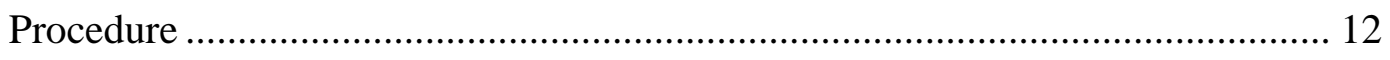

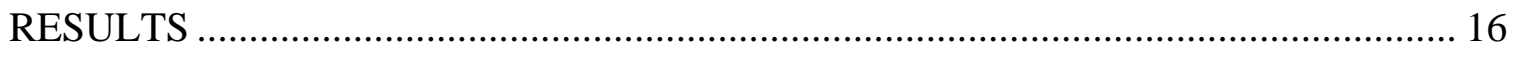

Inheritance and Harvesting Behavior ................................................................. 16

Inheritance and Attitudes about the Commons Dilemma ....................................... 16 


\section{TABLE OF CONTENTS (continued)}

Page

Attitudes about the Commons Dilemma and Harvesting Behavior....................... 18

Inheritance and Sense of Responsibility .............................................................. 18

Inheritance and Endorsement of Environmental Attitudes.................................... 18

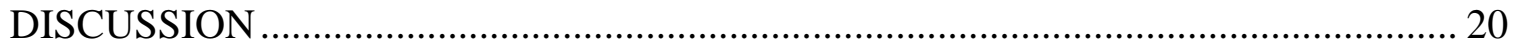

Behavior and Attitudes in the Commons Dilemma .............................................. 20

Responsibility for the Outcome of the Commons Simulation................................ 25

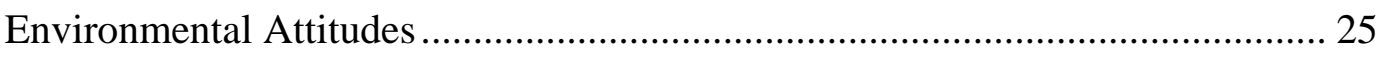

LIMITATIONS AND FUTURE DIRECTIONS .......................................................... 27

REFERENCES ……………………………………...................................... 29

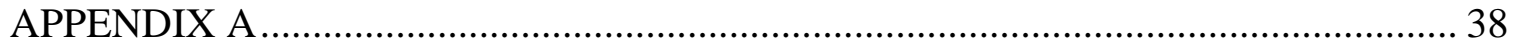




\section{LIST OF TABLES}

Table Page

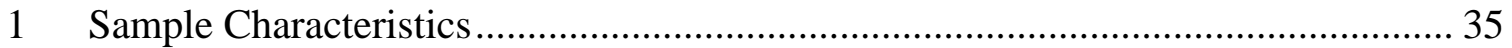

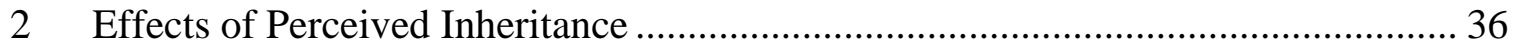

3 Summary of Regression Analysis for Variables Predicting Total Individual Harvest in the Commons Dilemma Simulation...................................................................... 37 


\section{INTRODUCTION}

How and why individuals choose to cooperate with others or behave individualistically is extremely important in everyday life, and is indeed a fundamental issue of human behavior and philosophy. Situations involving such cooperation and defection are referred to as social dilemmas (e.g., Penner, Dovidio, Pillavian, \& Schroeder, 2005) and have long been of interest to social psychologists (e.g., Dawes, 1980; Kopelman, Weber, \& Messick, 2004). An especially pressing manifestation of the social dilemma involves cooperation and defection in maintaining diminishing yet renewable resources like fish stock, forests, and clean water. Maintenance of these resources can be a matter of life and death in the cases of clean water and food resources like fertile soil and fish, or simply impact quality of life. The social dilemmas that arise when interacting with real or simulated resources are called commons dilemmas or resource dilemmas (e.g., Kopelman et al., 2002).

A commons is some type of diminishing yet renewable common resource to which many individuals have relatively free access (Bell, Greene, Fisher, \& Baum, 2001; Hardin, 1968). Such shared resources come in several forms. One type involves harvesting from a common resource. Examples of this type of commons include fishstock, forests, fertile soils and clean water. Another type of commons is the public good

dilemma which involves a common resource to which individuals must give (or choos not to). Examples of this type include public radio/TV, a tax base, and parks with admission fees but no staff to enforce them. A third type of commons dilemma is the commons of 
pollution (e.g., Hardin, 1968). In this version, individuals and groups interact with a resource that can only process so much input in a given period of regeneration. Examples of this type include air and water resources that can only process so much human pollution within a given time frame without adversely impacting living populations.

Though distinct, these different types of dilemmas have the same underlying structure (e.g., Bell et al., 2001; Brewer \& Kramer, 1986). Individuals have simultaneous yet opposing motivations: maximize personal gain from the resource while minimizing personal cost. Hardin (1968) asserted that this desire to maximize personal gain is rational at the individual level. For example, individual fishers have a motivation to harvest as many fish as possible, because in doing so, they maximize their financial gain and can thus provide more for their families and/or company. Likewise, individuals have a rational monetary motivation to not contribute to a collective resource if they can benefit from it for free (e.g., public media, parks) or if they do not need most of its services (e.g., tax base). Similarly, people have a rational motivation to get rid of waste products as cost effectively as possible. If a certain critical mass of individuals behaves this way, the resource can deplete at a rate (dependent on contextual factors) that doesn't allow for it's being sustained. This can lead to disaster if the resource is allowed to diminish such that its regeneration can no longer support those dependent upon it. On the other hand, individuals can choose to behave more conservatively at a rate that will allow the resource to remain. These simultaneous yet opposing choices (cooperation and defection) are at the heart of all social dilemmas (e.g., Bell et al., 2001), and the commons dilemma is no exception. 


\section{REVIEW OF THE LITERATURE}

There is a rich literature on commons dilemmas. Gifford and Hine (1997a) outlined necessary components one need be aware of to measure cooperation in commons dilemmas: "the number of harvesters, the amount of the resource, the rate of resource regeneration, and the size of the harvests” (p. 29). Researchers must know the specifics of these factors to be able to determine if something that may be an ambiguous behavior is actually cooperative.

\section{Factors Associated with Cooperation in Commons Dilemmas}

In the experimental method, researchers have investigated many factors that affect (or don't affect) cooperative behavior in commons dilemmas. These include, but are not limited to: personality (e.g., Koole, Jager, Vlek, \& Hofstee, 2001; Smith \& Bell, 1993); gender (e.g., Cadsby \& Maynes, 1998); motives (e.g., Liebrand, Jansen, Rijken, \& Suhre, 1986; Liebrand \& van Run, 1985; Loomis, Samuelson, \& Sell, 1994; Van Lange \& Kulhman, 1994); empathy for or attraction to others (e.g., Batson, Batson, Todd, Brumett, Shaw, \& Aldequer, 1995; Smith, Bell, \& Fusco, 1989); communication (e.g., Kerr \& Kaufman-Gilliand, 1994; Bouas \& Komorita, 1996); information availability (e.g. Bonacich, 1986; Loomis et al., 1994; Jager, Jannsen, \& Vlek, 2002); cognitive biases (Gifford \& Hine, 1997); reinforcers/payout from harvest (e.g., Birjulin, Smith, \& Bell, 2001; Martichuski \& Bell, 1991; Edney \& Bell, 1984; 1987); punishments (Bell, Petersen, \& Hautaluoma, 1989; Harvey, Bell, \& Birjulin, 1993); power (e.g. Galinsky et al., 1993; Mannix, 1993); structure of the resource (e.g. Brewer \& Kramer, 1986; 
Herlocker et al., 1997, Fleishman, 1988; Martichuski \& Bell, 1991); freedom in harvesting choice (Edney \& Bell, 1987); group size (e.g., Brewer \& Kramer, 1986; Sato, 1988; Savage, 2001); and priming methodologies (e.g., Galinsky et al., 2003).

\section{Environmental Attitudes and Commons Dilemmas}

One line of research involves the use of commons dilemma simulations in conjunction with measures of environmental attitudes. These can be measured, among other ways, in regards to how much value an individual places upon the natural environment and in how an individual behaves in relation to the natural environment (e.g., Garderner \& Stern, 2002; Kopelmen et al., 2004). In regard to the former, individuals can hold a homo-centric perspective in which they value the environment solely in its usefulness to human beings; individuals who hold an eco-centric perspective value the environment and ecosystems in their own right (Garderner \& Stern, 2002). In regard to environmentally significant behavior, individuals can behave individualistically, competitively, cooperatively, or altruistically (e.g., Kopelmen et al., 2004). Most research has focused on whether or not measures of environmental attitudes can predict behavior in the dilemma. Mixed results have been found. For example, one study found that measures of environmental concern did not predict commons dilemma behavior (Smith \& Bell, 1993). In that study only competitive personality could account for behavior in the dilemma. A more recent study (Kortenkamp \& Moore, 2006) found that when investigated in conjunction with measures of concern for future consequences, measures of environmental attitudes did predict cooperation in a commons dilemma. What are not 
present in the environmental attitudes/commons dilemma literature are studies in which measures of environmental concern follow an experimental manipulation. Perhaps situational primes resulting from a specific commons dilemma scenario can affect how an individual endorses measures of environmental values.

\section{Commons Dilemmas in the Real World}

Of course, commons dilemmas occur naturally in the real world, and to maximize our understanding of how actors behave in such situations, researchers have employed correlational and case study approaches to investigate factors present in actual settings (e.g., Buck-Cox, 1985; Gardener \& Stern, 2002). A couple of examples are worth noting. In the village of Torbel, Switzerland, a small group of cattle farmers has been operating a shared grassland commons since the late $13^{\text {th }}$ century. In this village, grazing lands are open for as many cows as a family can feed in a given winter. Also, their communal forests are harvested just once annually (to aid in detection of infractions), with the work and proceeds being split evenly among the families who are qualified (Buck-Cox, 1985; Gardener \& Stern, 2002). In another case, Maine lobster-catchers have been able to maintain a stable harvest for decades, even while other similar operations have nearly depleted their resource. There, the lobster-catchers, intimately aware of their area, have divided up the various areas in which lobsters are caught. By law, however, a licensed individual can harvest from any area. The Maine lobster-catchers have developed informal systems in which all harvesters within a given area (every lobster-catcher in the state would obviously constitute too large of a group to manage) know who is permitted to harvest in which areas and when. Infractions are punished with warnings. Repeated infractions may be followed up with destruction of 
one’s equipment. This mutually agreed upon system has allowed the lobster yield to remain healthy (Gardener \& Stern, 2002).

In thinking of real life examples of commons dilemmas, one factor comes to mind that is present in nearly every real life commons dilemma but that has not been investigated in the laboratory: inheritance. In nearly all types of commons, from fish stock to clean water to forests, individuals have inherited a resource from another group of people who harvested the resource previously (e.g., another generation). It seems logical that the behavior of a previous group and the norms and/or situational characteristics that result might affect future harvesting decisions. This could happen in one of several ways.

One is that a modeling effect may occur. That is to say, individuals told something about a previous group’s harvesting behavior may see their behavior as a norm upon which to base their own harvesting. Prior research provides strong support for the idea that people learn from observing the behavior of others (e.g., Bandura, 1986). Other research suggests that such modeling effects can apply to commons dilemmas (e.g., Nordlund \& Garvill, 2003).

However, based on other past research one might reasonably expect inheritance manipulations to affect behavior in one or both of two other counterintuitive ways. Those in experimental conditions in which others behaved either conservatively or in an exploitive manner with a resource might behave differently than their models. In other words, those who believe that others behaved conservatively with a resource may 
actually behave in an exploitive manner themselves and those who believe that others behaved in an exploitive manner may actually behave conservatively themselves.

In regard to conditions under which individuals believe that previous others have behaved conservatively, some research suggests that when a resource is plentiful (e.g., Edney, 1979) individuals will try to get as much as they can while they can. For example, in an original commons dilemma study, Edney (1979) found that many groups could not get past the first round of harvesting. With the perception of a bountiful resource, too many participants fell victim to the tragedy of the commons and over-harvested. Other research suggests that giving participants a message that implies that a current collective of harvesters has improved a resource over time can encourage them to free-ride (e.g., Vasi \& Macy, 2003). However, if all free-ride in hopes that others will conserve, the resource can deplete at a detriment to all. In regard to inheritance, given a message that past generations have grown a resource and left plenty behind might also promote such a free-riding effect.

In regard to conditions under which individuals believe that previous harvesters have behaved in an exploitive manner, other past research suggests that when a resource is perceived to be dwindling individuals will compensate by conserving (e.g., Loomis et al., 1994; Koole, Jager, van den Berg, Vlek, \& Hofstee, 2001). For example, Loomis and colleagues (1994) found that when groups of individuals harvested from a shared resource that began to reach very low levels, they reduced their harvesting to slow the depletion. This is especially intriguing given that in this study participants were measured to be either cooperative or competitive in personality. Overall, cooperative subjects 
harvested less, but the depletion of the resource caused both types of individuals to behave more conservatively. Other research suggests that conditions in which a participants' yield from a shared resource is yoked to the outcome of the group promote cooperation (Edney \& Bell, 1984). In the current research, participants lose all chances of gain from the resource if their group depletes it totally. Under such circumstances, one might expect even those who believe that a supposed previous group behaved in an exploitive manner may behave cooperatively. A somewhat less similar and relevant finding is that when over-harvesters cannot be identified, cooperation within a group increases (Bonacich, 1976). The present research employs a paradigm in which the previous generation of harvesters is not identifiable. As such, in conditions in which participants believed a previous group behaved in an exploitive manner, one might expect the abstract nature of the past defectors to promote group cooperation instead of an individualistic free-for-all.

To investigate these possibilities (modeling effects, counterintuitive behavior for those following conservative or exploitive harvesters), I conducted a study in which individuals believed that a previous group behaved conservatively, sustainably, or in an exploitive manner with a resource. As a function of this manipulation, participants also believed that they would be passing the resource on to another group. A control group received no such prime and played the game as normal.

As this area of research (inheritance and legacy) is new to commons dilemmas, several research questions, rather than hypotheses, are presented. 
Inheritance and Behavior in the Commons

In regard to inheritance and actual behavior in the simulation, one of three outcomes seems possible:

Inheritance condition could impact individual total harvest in the commons dilemma in a social-cognitive fashion. That is, participants in the experimental conditions would behave similarly to the group before them.

Inheritance condition might instead impact individual total harvest in the commons dilemma simulation such that those in the conservative condition will harvest more than those in the control and sustainable condition. This would be because those in the conservative condition would feel most justified in harvesting heavily because of the perception of a plentiful resource.

Finally, inheritance condition could impact individual total harvest in the commons dilemma such that those in the exploitive condition will harvest less than those in the control and sustainable conditions. This would be because those in the exploitive condition would harvest lightly to compensate for the low level of the resource.

Inheritance and Sense of Obligation to Preserve the Resource

This study also addresses how the inheritance conditions might impact individuals' sense of obligation to preserve the resource. Several possible outcomes seem possible in regard to obligation: 
In a social learning fashion, those in the conservative condition might feel the highest sense of obligation to preserve the resource, followed by the sustainable and exploitive conditions, in that order.

Since the resource is in danger of depleting, those in the exploitive condition might feel the highest sense of obligation to preserve it, followed by the sustainable and conservative conditions, in that order.

Finally, those in the two extreme conditions (conservative, exploitive) might feel the highest sense of obligation to preserve the resource, for their own reasons as outlined above. Those in the conservative condition will see a standard which they will not want to diminish. Those in the exploitive condition will not want the depletion to continue.

\section{Hypotheses}

This study is also concerned with how sense of obligation to preserve the resource might impact actual behavior in the dilemma. Based on cognitive dissonance theory (Festinger, 1957), it is expected that participants will behave in a manner consistent with their previously stated level of obligation to preserve the resource. One hypothesis is offered to this end.

Hypothesis 1. Those with a higher sense of obligation to preserve the resource will harvest less than those with a lower sense of obligation. 
Inheritance and Participants’ Beliefs about Peers

Hypothesis 2. Inheritance condition will impact belief about the conservative behavior of others such that those in the conservative condition will believe that more of their peers would conserve the resource than those in the sustainable and exploitive conditions, in that order.

Hypothesis 3. Inheritance condition will impact belief about the exploitive behavior of others such that those in the exploitive condition will believe that more of their peers would exploit the resource than those in the sustainable and conservative conditions, in that order.

Hypothesis 4. In a free-riding effect, those who believe that more of their peers would act to preserve the resource will harvest more than those who believe that less of their peers would act to preserve the resource.

Hypothesis 5. In a compensatory effect, those who believe that more of their peers would exploit the resource will harvest less than those who believe that less of their peers would exploit the resource.

Perception of Responsibility for Commons Outcome

Hypothesis 6. Those who harvest more will profess greater responsibility for the outcome of the commons simulation than those who harvest less. 


\section{METHOD}

\section{Participants}

Participants were recruited through Humboldt State University’s online psychology research pool system. They were awarded class credit for their participation as well as entries into a raffle. Sixty-six participants (64\% female; $n=40)$ played the commons dilemma simulation game in groups of three to five, yielding 15-16 participants in each of the four groups. Two thirds of the sample was between the ages of 18 and 21 $(n=40) ; 15 \%$ were between the ages of 22 and $25(n=9) ; 13 \%$ were between 26 and 30 $(n=8)$; and the remaining $8 \%$ were over $30(n=5$; see table 1$)$. In regard to ethnicity, nearly $70 \%$ of the participants were white, $15.3 \%$ were Hispanic, $8.5 \%$ were multiethnic, 3.4\% were Haitian, 1.7\% were African American, and 1.7\% were Asian American.

\section{Procedure}

Research assistants told participants in three experimental groups that they had inherited a common resource from a previous group and that they would in turn pass it on to another. The researchers informed those in the conservative condition that the previous group grew the resource over time; those in the sustainable condition that the previous group had kept the level of the resource consistent over time; and those in the exploitive group that the previous group had depleted the resource over time. A control group received no such prime. Participants played the commons game in groups of three 
to five. In groups of three the players started with fifteen points in the resource; in groups of four they started with twenty points; and in groups of five players started with twentyfour points. In this way, if all of the players harvested the maximum amount for the first two rounds, the resource would be depleted.

When participants entered the classroom, a research assistant instructed them to sit at least one seat apart. To start the game, the researcher handed out thorough instructions for the game (see Appendix) and read them aloud to the participants as they followed along. The researcher told participants in experimental conditions that they were inheriting a resource from a previous group and told them the amount of points with which the previous group had began, and how many points they left behind. The researcher told participants that they could harvest nothing or up to three points per round, and that following each round of harvesting the pool would be replenished by fifty percent. Each point earned the participant an entry into a drawing for \$20 and gift certificates for a local pizza restaurant and a local record store. Overall, the total prize was worth approximately $\$ 50$. If the participants in a group completely depleted the resource, they would lose all of their entries into the drawing. Thus, a true dilemma existed in that participants had an incentive to both maximize their personal gain in raffle entries and preserve the resource so that they did not lose the chance of winning.

The instructions sheet also contained three questions that measured whether or not the participants understood the rules of the game (e.g., "what happens if the pool drops to zero?”) The researcher then went to each participant to see if he or she answered the 
questions correctly. If a participant did not understand anything, the researcher explained it again and made sure that he or she understood the rules.

Following the instructions participants were given a questionnaire (see Appendix). As a manipulation check, in the experimental conditions we asked participants to write down how much the previous group started with and how much they left behind. In all conditions, participants were then questioned on what percentage of their peers would preserve or exploit the resource (on interval 10 point scales) and their own sense of obligation to preserve it (on an ordinal nine point scale).

Following this, the game began. Utilizing a procedure used by others in similar research (e.g., Gifford \& Hine, 1997b) the game was conducted using a simple simulation of points on a chalkboard. The researcher drew out a grid on the board to measure the total group harvest for each round while privately recording individual harvests. To nullify any possible threats to internal validity, participants were instructed not to speak to one another during the game. The lack of interaction between players in conjunction with the fact that the objective size of the resource held constant across conditions allowed isolation of the factor of inheritance (or behavior of others) as the sole influence on individual harvesting behavior. During each round, participants held up a card and showed only the researcher their harvesting choices. After all players harvested, the researcher calculated the total harvest for the group and added the replenishment of fifty percent. The commons simulation lasted for five rounds, though to avoid end of game effects the participants were told that the game would last up to ten. 
Following the game, participants were given a questionnaire (see Appendix) on which they were asked to indicate their sense of responsibility for the outcome of the game and also completed a final measure, the Humboldt Environmental Attitudes Test (HEAT; Porter, Porter, \& Campbell, 2007). Participants were then called up one at a time to write their name and contact information on a slip of paper that indicated the number of entries into the raffle they had received. At this point, participants were thanked for playing the game and debriefed. At the end of the semester, the raffle was conducted and one player won the prize. 


\section{RESULTS}

All relevant variables were checked for assumptions of normality and homogeneity of variance. The obligation and responsibility variables underwent squareroot transformations to correct for positive skew.

Inheritance and Harvesting Behavior

To investigate the effects of perceived inheritance on harvesting behavior, a oneway analysis of variance procedure was ran with inheritance condition as a fixed factor and individual total harvest as dependent variable. Inheritance condition did not predict harvesting behavior $(F<1)$. Thus, none of the first three research questions received direct support.

Inheritance and Attitudes about the Commons Dilemma

However, inheritance condition did predict the level of obligation individuals felt

to preserve the resource, $F(3,59)=3.8, p=.01, \eta^{2}=.16$. Follow up multiple comparison (LSD) testing revealed that those in the conservative condition $(M=7.8, S D=0.83)$ were more likely than those in the sustainable $(M=6.1, S D=0.83)$ or control conditions $(M$ $=6.1, S D=2.1)$ to feel a higher sense of obligation to preserve the resource $(p s<.01)$. Those in the exploitive condition $(M=7, S D=0.82)$ did not differ at traditional levels of significance from any of the other three conditions but did approach significant differences from those in the sustainable group $(p=.08)$ and the control condition $(p=.12$; 
See Table 2). Thus, accepting that the exploitive condition approached significant difference from the sustainable and control conditions, the sixth research question is supported: those in the two extreme groups felt the highest sense of obligation to preserve the resource.

Inheritance condition also predicted participants’ beliefs about the conservative behavior of their peers, $F(3,59)=4.2, p=.01, \eta^{2}=.18$. Follow up multiple comparison (LSD) testing revealed that those in the conservative condition $(M=7.1, S D=2.6)$ were more likely than those in the sustainable $(M=4.3, S D=2.4)$ and control conditions $(M=$ $5.1, S D=1.7)$ to believe that a high percentage of their peers would preserve the resource if given the same opportunity ( $p$ ’s<.01). The conservative group approached significant difference from those in the exploitive condition $(M=5.7, S D=2.5 ; p=.075$; See Table 2). Thus, Hypothesis 2 is partially supported. The unsupported portion of this hypothesis is that those in the sustainable condition, on average, believed that less of their peers would preserve the resource than did those in the exploitive condition. There was no effect of inheritance on beliefs about the exploitive behavior of peers, $F(3,59)=1.9$, $p$ $=.14$. Thus, hypothesis 3 is not directly supported. However, a t-test investigating only the exploitive and conservative conditions reveals that those in the exploitive condition $(M=6.8, S D=2.4)$ believed that more of their peers would harvest at the maximum level each round than did those in the conservative condition $(M=4.6, S D=2.3), t(30)=-2.5$, $p=.02, d=.93$. Thus, partial support is found for hypothesis 3 . 
Attitudes about the Commons Dilemma and Harvesting Behavior

A hierarchical regression model incorporating sense of obligation to preserve the resource at step one, belief that others would preserve the resource at step two, and belief that others would exploit the resource at step three predicted individual total harvesting behavior, $F(2,60)=4.7, p=.01, R^{2}=.14$ (a regression model incorporating all possible interactions as further steps found no interaction effects). Those with a higher sense of obligation to preserve the resource were more likely to behave conservatively with the resource than those with a lower sense of obligation. This supports Hypothesis 1 . Those who believed that more of their peers would preserve the resource were less likely to behave conservatively with the resource than those who believed that fewer of their peers would preserve it (See Table 3). This supports hypothesis 4. Perception of the exploitive behavior of peers did not predict harvest behavior, thus, hypothesis 5 is not supported.

\section{Inheritance and Sense of Responsibility}

Regardless of how they behaved in the commons dilemma (cooperatively, individualistically) participants felt the same level of responsibility, $F<1$. They tended to feel proportionally responsible for the outcome. Thus, hypothesis 6 is not supported.

\section{Inheritance and Endorsement of Environmental Attitudes}

Participants completed the HEAT packet following the experimental manipulation. With no previous research to draw upon, I had no a priori hypothesis for how such a prime might affect participants’ endorsement of environmental attitudes. 
Interestingly, the manipulation did affect such endorsements. The HEAT measure consists of four factors related to environmental behavior. One relates to prosocial behavior. Another involves whether or not an individual is more competitive or cooperative. A third involves whether someone places value on the environment solely in its short-term usefulness to humankind or whether he or she sees value in ecosystems and non-human nature in and of themselves. A final factor involves belief in the level of impact humans can have on the environment (Porter et al., 2007).

Inheritance did not predict how participants endorsed the Prosocial and Competitive-Cooperative factors. It did however predict how participants endorsed the two factors most closely related to the environment: Ecocentric-Homocentric thinking, $F$ $(3,62)=3.5, p=.02, \eta^{2}=.14$, and Beliefs in Impact, $F(3,62)=3.1, p=.03, \eta^{2}=.13$

In regard to the Ecocentric-Homocentric factor, those in the exploitive condition $(M=63.5, S D=6.2)$ were more likely to endorse ecocentric thinking than those in the conservative $(M=58.3, S D=5.2)$ and sustainable $(M=58, S D=6.5)$ conditions ( $p s$ $<.05)$. The control condition $(M=62.4, S D=6.5)$ did not differ significantly from any of the experimental conditions (see Table 2).

In regard to the Beliefs in Impact factor, the trend was repeated. Those in the exploitive condition $(M=9.5, S D=0.81)$ were more likely to agree with statements which claimed that humankind can and does impact the natural environment and its systems than were those in the conservative $(M=8.3, S D=1.6)$ and sustainable $(M=8.1$, $S D=1.7)$ conditions ( $p$ 's $<.05$; see Table 5$)$. Those in the control condition $(M=8.9, S D$ $=1.4$ ) did not differ significantly from any of the experimental conditions. 


\section{DISCUSSION}

\section{Behavior and Attitudes in the Commons Dilemma}

Participants played a commons dilemma simulation in which experimental groups were told that they had inherited a shared resource from a previous group and that they would in turn leave the resource behind for another group. It was found that inheritance condition predicted sense of obligation to preserve the resource and beliefs about the percentage of the participants' peers who would conserve the resource. Those in the conservative condition were more likely to feel higher obligation and to believe that more of their peers would act to preserve the resource. Obligation and beliefs about peers predicted behavior with the resource such that those higher in obligation behaved more cooperatively as did those who thought that fewer of their peers would preserve the resource. Finally, inheritance condition impacted endorsement of environmental attitudes, such that those in the exploitive condition were more likely to report being more proenvironmental.

What does this study tell us? Why did the results fail to find support for any of the alternative hypotheses of 1a-c? The data suggest that thoughts and behavior in commons dilemmas may not always be in synch. This is certainly consistent with other research which has found that cognitive biases (e.g., fundamental attribution error, false consensus bias) are rampant in commons dilemma paradigms (Gifford \& Hine, 1997). This study specifically demonstrates that perceived inheritance does not affect harvesting behavior but does have an impact on attitudes about the commons dilemma situation, such that 
some are likely to feel more obligated to preserve a resource or to believe that others would preserve it. Perhaps this is a general trend in human behavior; perhaps it reflects the artificial nature of the inheritance and legacy manipulation. To piece out these possibilities, more laboratory research in conjunction with case studies involving actual conditions of inheritance will need to be conducted.

That being said, this study leaves us with plenty to think about. Certainly, the data indicate that perceived inheritance has an effect on attitudes in a commons dilemma. We see clear, statistically significant effects (with reasonable effect sizes) of inheritance conditions on attitudes in a commons dilemma. Why might those in the conservative and exploitive conditions have higher mean scores than the sustainable and control conditions in regard to their self-reported sense of obligation to preserve the resource? For those in the conservative condition, I suggest that a behavioral norm was generated through the perception of a growing resource. This could have led participants to be more likely to feel a sense of obligation to preserve the resource in their own right. For those in the exploitive condition, I suggest that the perception of a depleting resource acted as a call to action, prompting those in this condition to feel obligated to keep the resource alive.

Though inheritance did not impact behavior, this sense of obligation did account for behavior in the commons dilemma. Those who felt a higher sense of obligation to preserve the resource acted accordingly and harvested less of the resource. This makes sense in light of cognitive dissonance theory (Festinger, 1957). Participants completed the obligation measure before the game. Having just professed a high or low sense of 
obligation to preserve the resource, participants behaved in a manner that was consistent with their attitudes.

Inheritance impacted the percentage of peers participants believed would act to preserve the resource. Those in the conservative condition felt that more of their peers would preserve the resource than did participants in any of the other three conditions. This can likely be explained via a social learning effect. Having been told that a previous group grew a resource over time gave participants examples of relevant models. Similarly, this could account for why those in the sustainable, exploitive, and control groups believed that less of their peers would preserve the resource. Another possibility is that perhaps a quasi-false-consensus effect emerged wherein participants in the conservative condition felt that the behavior of the previous group was indicative of how most participants would behave. This could also account for why participants in the other groups felt that less would preserve the resource.

Beliefs about the conservative behavior of peers predicted actual behavior in the commons dilemma. Those who believed that more of their peers would act to preserve the resource were more likely to harvest more from the resource. It seems that those individuals who felt that others would take steps to preserve the resource fell victim to free-riding tendencies. This is consistent with other research on free-riding effects (e.g., Diehle \& Stroebe, 1985; Vasi \& Macy, 2003). When participants believe that others have or will ensure that the resource remains, free-riding is encouraged (Vasi \& Macy, 2003).

There was no main effect of inheritance condition on participants' estimates of the percentage of their peers who would harvest the maximum amount each round. However, 
a follow up T-test revealed that those in the two extreme conditions differed significantly on this measure, such that those in the exploitive condition believed that a much higher percentage of their peers would exploit the resource than did those in the conservative condition. In parallel to the explanation of the differences in beliefs about conservative behavior, this contrast is consistent with social cognitive theory and false consensus effects.

Taken together, the results discussed to this point paint an interesting picture of the effects of perceived inheritance on behavior in commons dilemmas. Inheritance alone does not impact behavior but it does impact sense of obligation to preserve the resource. Those in the two extreme conditions report a higher sense of obligation; they seem to want to preserve the resource more, but this does not translate to a significant effect on actual behavior in the dilemma. Why might this be so? The estimates of peer behavior may shed light on this. Those in the conservative condition were more likely than all of the other conditions to think that a higher number of peers would preserve the resource. In a free-riding fashion, those who believed this about their peers harvested significantly more of the resource. Even though they felt more of an obligation to preserve the resource than those in the sustainable and control conditions, the temptation to free-ride seems to have kept their conservation in check. Conversely, those in the other conditions believed that less of their peers would preserve the resource. Those who believed this harvested less, perhaps in an effort to compensate for the perceived behavior of others. Though no main effect of inheritance was found for beliefs about the exploitive behavior of peers, an important contrast was found between the exploitive and conservative 
conditions. In comparison to the conservative condition, those in the exploitive condition were significantly more likely to believe that others would maximize their harvest each round, which could plausibly explain why a group shown an exploitive norm did not over-harvest.

In consideration of all of this, we now start to see the true effect of inheritance on harvest behavior, as illuminated through obligation to preserve the resource and the variables involving participants’ beliefs about peer behavior. The variables involving beliefs about peer's behavior with a common resource seem to indicate that the reverse of what might be expected from a social-learning perspective may have taken place, wherein the two extreme groups behaved in a manner opposite of the norms demonstrated by a supposed previous group of harvesters. Though the effect of inheritance was not significant, the conservative condition had the highest mean individual total harvest. Moreover, without the temptation for free-riding that came from the beliefs that others (previous group) had behaved conservatively and that others (peers) would behave conservatively, those in the exploitive condition behaved more conservative. This effect cancelled out any possibility of a main effect of inheritance, and clearly rejects the idea that a social learning perspective, operationalized specifically through perceived inheritance, might apply to the behavior of actors in a simulated commons dilemma. Thus, it now seems that hypotheses $1 \mathrm{~b}$ and 1c (those suggesting that the two extreme groups would behave in a manner opposite to the previous group) receive indirect support. 
Responsibility for the Outcome of the Commons Simulation

An intriguing finding from this study is that regardless of how conservative or exploitive participants behaved in the commons dilemma simulation, they felt a proportional amount of responsibility for the outcome. Obviously, if a group of harvesters contains one exploiter and two conservers, the responsibility for the outcome is not equally shared. This is another example of attitude/behavior inconsistency present in the commons dilemma. I speculate that this may be simply a phenomenon of the experimental paradigm. That is to say, since participants did not know how others harvested, they likely counted the number of people in the room and assigned themselves proportional blame. That being said, this finding is worthy of further investigation in an effort to understand why cooperative and competitive players would feel the same level of responsibility, perhaps with qualitative items directly assessing this variable. On the other hand, perhaps this is indicative of a robust finding. If it's the case that overharvesters feel the same amount of responsibility as cooperators, this would have implications for the crafting of pro-environmental messages. Perhaps advertisements that seek to promote cooperation with a resource should highlight the fact that when one overharvests, he or she is more to blame for environmental problems. This might prompt some to alter their environmentally significant behavior in a positive way.

\section{Environmental Attitudes}

Finally, the inheritance manipulation affected participants' endorsements of environmental beliefs and values. Specifically, participants who believed that those in a 
previous group had behaved in an exploitive manner with the resource were significantly more likely to endorse eco-centric and believe that humankind can have an impact on the natural environment values than the other two experimental conditions. This finding is of extreme importance. It suggests that priming individuals with thoughts of the exploitation of an actual resource can affect them in a similar way, such that they value the natural environment more. This could have profound implications for the advertising strategies used by governments and environmental organizations who seek to increase populations’ pro-environmental sentiments. Pro-environmental advertisers would be wise to highlight the fact that many crucial resources are depleting at dangerous rates (e.g., fish stocks, fertile soil, clean water, forests; Gardener \& Stern 2002). Hopefully such a message can act to promote a more pro-environmental outlook in the minds of actors in the global commons. 


\section{LIMITATIONS AND FUTURE DIRECTIONS}

A limitation of this study is the relatively small sample size. While this is consistent with some studies in the literature, it is far fewer than many others. It's difficult to gauge just how limiting this is, given that the present study is investigating an entirely new factor in experimental commons dilemma research. Another major limitation is the laboratory setting, as is the case with all commons dilemma simulations. Harvesting abstract points from a chalkboard is very much removed from harvesting trees in a forest or fish from an ocean or river. As such, we need to take the results of this (and all commons studies) with a grain of salt. However, barring expensive research in which one maintained an actual ecological commons and recorded data on how and why people harvested the way they did, such controlled laboratory research, in conjunction with case-studies of actual commons, is useful in helping us to understand behavior with shared resources.

Certainly, more research is needed to investigate the factor of inheritance. Another study that is very similar would be excellent in confirming the attitudinal effects from inheritance conditions as well as the finding that inheritance does not impact behavior. In this study, two other major factors were present that may have affected the results: a severe punishment such that any group that depleted the resource completely lost all entries into the drawing and a replenishment rate of $50 \%$ each round. A more elegant 4 x 2x 2 study in which the inheritance and control conditions were crossed with two levels of punishment (lose all entries vs. get to keep them all regardless of group 
outcome) and two levels of replenishment (e.g., 50\% vs. 10\%) might be better able to investigate the effects at work in this design. 


\section{REFERENCES}

Bandura, A. (1986). Social foundations of thought and action: A social cognitive theory. Upper Saddle River, NJ: Prentice-Hall

Batson, C. D., Batson, J. G., Todd, R. M., Brummett, B. H., Shaw, L. L., \& Aldequer, C. M. R. (1995). Empathy and the collective good: Caring for one of the others in a social dilemma. Journal of Personality and Social Psychology, 68, 619-631.

Bell, P. A., Petersen, T. R., \& Hautaluoma, J. E. (1989). The effect of punishment probability on overconsumption and stealing in a simulated commons. Journal of Applied Social Psychology, 19, 1483-1495

Bell, P. A., Greene, T. C., Fisher, J. D., \& Baum, A. (2001) Environmental Psychology ( $5^{\text {th }}$ ed.). Orlando: Harcourt.

Birjulin, A. A., Smith, J. M., \& Bell, P. A. (2001). Monetary reward, verbal reinforcement, and harvest strategy of others in the commons dilemma. The Journal of Social Psychology, 133, 207-214.

Bonacich, P. (1976). Secrecy and solidarity. Sociometry, 39, 200-208.

Bouas K. S., \& Komorita, S. (1996). Group discussion and cooperation in social dilemmas. Personality \& Social Psychology Bulletin, 22, 1144-1150.

Brewer M. B., \& Kramer, R. M. (1986). Choice behavior in social dilemmas: Effects of social identity, group size, and decision framing. Journal of Personality and Social Psychology, 50, 543-549.

Buck-Cox, S.J. (1985). No tragedy on the Commons. Environmental Ethics, 7, 49-61 
Cadsby, C. B., and Maynes, E. (1998) Gender and free riding in a threshold public goods game: Experimental evidence. Journal of Economic Behavior and Organization 34, 603-620.

Dawes, R. M. (1980). Social dilemmas. In Rozenzweig, M.R. \& Porter, L.W. (eds.) Annual Review of Psychology (Vol. 31, pp. 169-193). Palo Alto, CA: Annual Reviews Inc.

Diehle, M., \& Stroebe, W. (1987). Productivity loss in brainstorming groups : Toward the solution of a riddle. Journal of Personality and Social Psychology, 53, (3), 497-509

Edney, J. J. (1979). The nuts game: A concise commons dilemma analog. Environmental Psychology and Nonverbal Behavior, 3, 252-254.

Edney, J. J., \& Bell, P. A. (1984). Sharing scarce resources: Group-outcome orientation, external disaster, and stealing in a simulated commons. Small Group Behavior, 15, 87-108.

Edney, J. J. \& Bell, P. A. (1987). Freedom and equality in a simulated commons. Political Psychology, 8, 229-243.

Festinger, L. (1957). A theory of cognitive dissonance. Stanford, CA: Stanford University Press.

Fleishman, J. A. (1988). The effects of decision framing and others' behavior on cooperation in a social dilemma. Journal of Conflict Resolution 32, 162-180

Galinsky, A. D., Gruenfeld, D. H., \& Magee, J. C. (2003). From power to action. Journal 
of Personality and Social Psychology, 85, 453-466.

Gardner, G. T., \& Stern, P. C. (2002). Environmental problems and human behavior. Boston, MA: Pearson.

Gifford, R., \& Hine, D. W. (1997). Toward cooperation in commons dilemmas. Canadian Journal of Behavioural Science, 29, 167-178.

Gifford, R., \& Hine, D. (1997). “I’m cooperative, but you're greedy”: Some cognitive tendencies in a commons dilemma. Canadian Journal of Behavioural Science, 29, 257-265.

Hardin, G. (1968). The tragedy of the commons. Science, 162, 1243-1248.

Harvey, M. L., Bell, P. A., \& Birjulin, A. A. (1993). Punishment and type of feedback in a simulated commons dilemma. Psychological Reports, 73, 447-450.

Herlocker, C. E., Allison, S. T., Foubert, J. D., \& Beggan, J. K. (1997). Intended and unintended overconsumption of physical, spatial, and temporal resources. Journal of Personality and Social Psychology, 73, 992-1004.

Hertel, G., \& Fiedler, K. (1994). Affective and cognitive influences in a social dilemma game. European Journal of Social Psychology, 24, 131-145.

Kerr, N. L., \& Kaufman-Gilliland, C. M. (1994). Communication, commitment, and cooperation in social dilemmas. Journal of Personality and Social Psychology, 66, 513-529.

Koole, S. L., Jager, W., van den Berg, A. E., Vlek, C. A. J., \& Hofstee, W. K. B. (2001). On the social nature of personality: Effects of extraversion, agreeableness, and feedback about collective resource use on cooperation in a resource dilemma. 
Personality and Social Psychology Bulletin, 27, 289-301.

Kortenkamp, K. V., \& Moore, C. F. (2006). Time, uncertainty, and individual differences in decisions to cooperate in resource dilemmas. Personality and Social Psychology Bulletin, 32, 603-615.

Kopelman, S., Weber, J. M., \& Messick, D. M. (2002). Factors influencing cooperation in commons dilemmas: A review of experimental psychological research. In E. Ostrom, T. Dietz, N. Dolsak, P. C. Stern, S. Stonich, \& E. U. Weber, (Eds.), The Drama of the Commons (pp. 112-156). Washington, DC: National Academy Press.

Liebrand, W. B. \& van Run, G. J. (1985). The effects of social motives on behavior in social dilemmas in two cultures. Journal of Experimental Social Psychology, 21, 86-102.

Liebrand, W. B. G., Jansen, R. W. T. L., Rijken, V. M., \& Suhre, C. J. M. (1986). Might over morality: Social values and the perception of other players in experimental games. Journal of Experimental Social Psychology, 22, 203-215.

Loomis, D. K., Samuelson, C. D., \& Sell, J. A. (1994). Effects of information and motivational orientation on harvest of a declining renewable resource. Society and Natural Resources, 8, 1-18.

Mannix, E. A. (1993). Organizations as resource dilemmas: The effects of power balance on coalition forming in small groups. Organizational Behavior and Human Decision Processes, 55, 1-22.

Martichuski, D. K. , \& Bell, P. A. (1991). Reward, punishment, privatization, and moral 
suasion in a commons dilemma. Journal of Applied Social Psychology, 21, 1356-1369.

Nordlund, A. M. \& Garvill, J. (2003). Effects of values problem awareness, and personal norm on willingness to reduce personal car use. Journal of Environmental Psychology, 23, 339-347.

Penner, L. A., Dovidio, J. F., Piliavin, J. A., \& Schroeder, D. A. (2005). Prosocial behavior: Multilevel perspectives. Annual Review of Psychology, 56, 365-392.

Porter, M. K., Porter, B. E., \& Campbell, D. E. (2007, May). The Humboldt environmental attitudes test (HEAT). Poster session presented at the annual meeting of the Western Psychological Association, Vancouver, BC, Canada.

Sato, K. (1988). Trust and group size in a social dilemma. Japanese Psychological Research, 30, 88-93.

Savage, C.L. (2001). The effects of issue importance and group size differences on contribution rates and social identity in a public goods social dilemma.

Dissertation Abstracts International: Section B: The Sciences and Engineering, 62(3-B), 1647.

Smith, J. M., Bell, P. A., \& Fusco, M. E. (1989). The influence of attraction on a simulated commons dilemma. The Journal of General Psychology, 115, 277-283.

Smith, J. M., \& Bell, P. A. (1993) Environmental concern and cooperative/competitive behavior in a simulated commons dilemma. Journal of Social Psychology, 132, 461-468.

Smith, J. M. \& Bell, P. A. (2001). Environmental concern and cooperative-competitive 
behavior in a simulated commons dilemma. The Journal of Applied Social

Psychology, 132, 461-468.

Vasi, I. B., \& Macy, M. (2003). The mobilizer’s dilemma: Crisis, empowerment, and collective action. Social Forces, 81, 979-998. 
Table 1

Sample Characteristics

\begin{tabular}{lcc}
\hline Demographic Variable & $n$ & $\%$ \\
\hline Gender & & \\
$\quad$ Female & 40 & 64 \\
$\quad$ Male & 26 & 36 \\
Age Group & & \\
18-21 & 40 & 64 \\
$22-25$ & 9 & 15 \\
$26-30$ & 8 & 13 \\
$>30$ & 5 & 8 \\
Race/Ethnicity & & \\
White/European-American & 41 & 69.5 \\
Hispanic/Latino & 9 & 15.3 \\
Multi Ethnic & 5 & 8.5 \\
Haitian & 2 & 3.4 \\
African American & 1 & 1.7 \\
Asian & 1 & 1.7 \\
\hline
\end{tabular}


Table 2

Effects of Perceived Inheritance

\begin{tabular}{|c|c|c|c|c|c|c|c|c|}
\hline \multirow{2}{*}{$\begin{array}{l}\text { Dependent } \\
\text { Variable }\end{array}$} & \multicolumn{2}{|c|}{$\underline{\text { Conservative }}$} & \multicolumn{2}{|c|}{$\underline{\text { Sustainable }}$} & \multicolumn{2}{|c|}{ Exploitive } & \multicolumn{2}{|c|}{$\underline{\text { Control }}$} \\
\hline & $M$ & $S D$ & $M$ & $S D$ & $M$ & $S D$ & $M$ & $S D$ \\
\hline $\begin{array}{l}\text { Total } \\
\text { Individual } \\
\text { Harvest }\end{array}$ & $8.2 \mathrm{a}$ & 2.2 & $7.5 \mathrm{a}$ & 3.4 & $7.5 \mathrm{a}$ & 3.3 & $7.5 \mathrm{a}$ & 2.7 \\
\hline $\begin{array}{l}\text { Sense of } \\
\text { Obligation to } \\
\text { Preserve the } \\
\text { Resource }\end{array}$ & $7.8_{a}$ & 0.8 & $6.1_{b d}$ & 0.8 & 7.0 $0_{\mathrm{abcd}}$ & 0.8 & $6.1_{\mathrm{cd}}$ & 2.1 \\
\hline $\begin{array}{l}\text { Beliefs About } \\
\text { Percentage } \\
\text { of Peers Who } \\
\text { Would } \\
\text { Preserve the } \\
\text { Resource }\end{array}$ & $7.1_{\mathrm{a}}$ & 2.6 & $4.3_{b d}$ & 2.4 & $5.7_{\mathrm{abcd}}$ & 2.5 & $5.1_{c d}$ & 1.7 \\
\hline $\begin{array}{l}\text { Beliefs About } \\
\text { Percentage } \\
\text { of Peers Who } \\
\text { would Exploit } \\
\text { the Resource }\end{array}$ & $4.7_{\mathrm{ac}}$ & 2.3 & $6.1_{c}$ & 2.8 & $6.8_{b c}$ & 2.5 & $5.8_{c}$ & 2.6 \\
\hline $\begin{array}{l}\text { Endorsement } \\
\text { of the } \\
\text { Ecocentric- } \\
\text { Homocentric } \\
\text { factor }\end{array}$ & $58.3_{a c}$ & 5.2 & $58.0_{a c}$ & 6.5 & $63.5_{b d}$ & 6.2 & $62.4_{\mathrm{ad}}$ & 6.5 \\
\hline $\begin{array}{l}\text { Endorsement } \\
\text { of the Beliefs } \\
\text { in Impact } \\
\text { factor }\end{array}$ & $8.3 \mathrm{ac}$ & 1.6 & $8.1 \mathrm{ac}$ & 1.7 & $9.5_{b}$ & 0.81 & $8.8 \mathrm{ad}$ & 1.4 \\
\hline $\begin{array}{l}\text { Sense of } \\
\text { Responsibility } \\
\text { for Outcome } \\
\text { of the Game }\end{array}$ & $4.7 \mathrm{a}$ & 2.5 & $5.8_{a}$ & 2.7 & $4.6 \mathrm{a}$ & 2.9 & $3.8_{a}$ & 1.9 \\
\hline
\end{tabular}

Note: Values in the same row not sharing a subscript differ at $p<.05$ (see text for description of conditions approaching significant difference). 
Table 3

Summary of Regression Analysis for Variables Predicting Total Individual Harvest in the Commons Dilemma Simulation

\begin{tabular}{|c|c|c|c|}
\hline Variable & B & SE B & $\beta$ \\
\hline $\begin{array}{l}\text { Step } 1 \\
\text { Sense of Obligation to } \\
\text { Preserve the Resource }\end{array}$ & 2.7 & 1.02 & $.33^{\star}$ \\
\hline $\begin{array}{l}\text { Step } 2 \\
\text { Beliefs About Percentage of } \\
\text { Peers Who Would Preserve } \\
\text { the Resource }\end{array}$ & 0.31 & 0.15 & $.27^{\star \star}$ \\
\hline
\end{tabular}

Step 3

Beliefs About Percentage of Peers Who Would Exploit the $\begin{array}{lll}-0.03 & 0.14 & -.02\end{array}$ Resource

Note: $\mathrm{R} 2=.14(p=.01) .{ }^{\star} p=.01,{ }^{\star *} p=.04$ 
APPENDIX A

Materials 


\section{Harvest Game Instructions}

In the Harvest Game, each group shares a common resource pool. The researcher will inform you of the number of points in your group's pool at the beginning of the game. Each player can choose to harvest $0,1,2$, or 3 points from the pool each round by holding up one of the cards in front of them, showing it to the researcher only. Players will not speak to each other during the game and will not know how much other individual players have harvested. After each round, the researcher will inform you of the points remaining in your pool. The points remaining in the pool at the end of each round will be multiplied by 1.5. This means that if, for example, there are twelve points remaining after the first round of harvesting, six points will be added before the second round of harvesting. There will be up to ten rounds of harvesting, provided that the resource pool is not emptied. For each point that you harvest for yourself, you will receive one entry in a drawing for a $\$ 25$ gift certificate to The Works, a gift certificate for a large pizza from Big Pete’s New York Style Pizzeria, and a \$20 bill. That's over \$60 in cash and prizes. The drawing will be held the first week of May. If a group empties the pool, players lose all the points they harvested and cannot enter the drawing . If every player harvests 3 points each round, then the pool will be emptied. To ensure that you understand the rules of the game, please answer the questions below (circle your choice):

How do you indicate the number of points you want to harvest?
A) by saying the number of points out loud
$B$ ) by showing a card to the researcher only
C) by showing a card to the other players

What happens if a group empties the pool?

A) The game ends, and players enter the drawing.

$B)$ The game starts over, and players try again.

C) The game ends and players cannot enter the drawing.

Can players speak to each other during the game? Yes No

If, for example, there are 10 points remaining after Round 1, how many points will be added before Round 2 ?
A) 4
B) 5
C) 6 
Questionnaire A (control)

If all the students on campus participated in this study, what percentage do you think would take the maximum amount (3 points) each round? (circle your choice)
$0-10 \%$
$11-20 \%$
$21-30 \%$
$31-40 \%$
41-
$50 \%$
$51-60 \%$
$61-70 \%$
$71-80 \%$
$81-90 \%$
$91-$
$100 \%$

If all the students on campus participated in this study, what percentage do you think would choose to preserve the resource pool?
$0-10 \%$
$11-20 \%$
21-30\%
$31-40 \%$
41-
$50 \%$
$51-60 \%$
$61-70 \%$
$71-80 \%$
$81-90 \%$
91-
$100 \%$

If all the students on campus participated in this study, what do you think would be the average points taken each round?
0
1
2
3

On a nine-point scale, how obligated do you feel to preserve the resource pool?

Not obligated Extremely obligated

Demographic Data

What is your sex? Male Female
What is your age?
A) $18-21$
B) $22-25$
C) $26-29$
D) 30 or over

What is your race? 
Questionnaire A (experimental conditions)

The points in your group's pool have been inherited from a previous group of Harvest Game players. The previous group had the same number of players as your group. The number of points remaining in their pool at the end of their game was passed on to your group. Below, the researcher has written how many points the previous group started with and how many points they passed on to your group. The number of points remaining in your group's pool will be passed on to a future group. If your group's pool is emptied, then participants in the group depending on those points will not be able to play the game or enter the drawing, but they will still receive research participation credit.

The previous group started with points.

The previous group passed on points. This is how much your group will start with.

Please answer the following questions before the game begins.

If all the students on campus participated in this study, what percentage do you think would choose to maximize their own point totals? (circle your choice)

$0-10 \%$ $11-20 \%$

$21-30 \%$

$31-40 \%$

$41-50 \%$

$51-60 \% 61-70 \% \quad 71-80 \% \quad 81-90 \% \quad 91-100 \%$

If all the students on campus participated in this study, what percentage do you think would choose to preserve the resource pool? (circle your choice)

$0-10 \% \quad 11-20 \% \quad 21-30 \% \quad 31-40 \% \quad 41-50 \%$

$51-60 \% 61-70 \% \quad 71-80 \% \quad 81-90 \% \quad 91-100 \%$

If all the students on campus participated in this study, what do you think would be the average number of points taken each round? (circle your choice)

$0 \quad 1$

3

On a nine-point scale, how obligated do you feel to preserve the resource pool? (circle your choice)

$\begin{array}{cccccccc}1 & 2 & 3 & 4 & 5 & 6 & 7 & 8 \\ \text { Not obligated } & & & & & & & \\ \text { Extremely obligated }\end{array}$

The previous group started with group. Your group will start with points and passed on points to your points. (fill in the blanks)

Demographic Data

What is your sex? Male Female

What is your age?
A) $18-21$
B) $22-25$
C) $26-29$
D) 30 or over

What is your race? 


\section{Questionnaire B}

In percentage terms, how responsible do you consider yourself to be for the overall outcome of the game (i.e., for the number of points remaining in the pool at the end of the game)? (circle your choice)

$0-10 \%$

$11-20 \%$

$21-30 \%$

$31-40 \%$

$41-50 \%$

$51-60 \%$

61-70\%

$71-80 \%$

81-90\%

91-100\% 
The Humboldt Environmental Attitudes Test (HEAT)

Please circle the response that best corresponds to your level of agreement or disagreement with the statement. Please answer every item. If you are confused by the wording of an item or for any other reason, note that below the item, and answer as best as you can.

1. It's important to help other people even at a personal cost.

-2: Strongly Disagree -1: Disagree 0: Unsure 1: Agree 2: Strongly Agree

2. Equality is something we should all strive for

-2: Strongly Disagree -1: Disagree 0 : Unsure 1: Agree 2: Strongly Agree.

3. It is okay to alter nature if it benefits enough people.

-2: Strongly Disagree -1: Disagree 0: Unsure 1: Agree 2: Strongly Agree

4. I generally oppose environmental policies that limit personal freedoms.

-2: Strongly Disagree -1: Disagree 0: Unsure 1: Agree 2: Strongly Agree

5. It's wrong for human actions to harm the environment.

-2: Strongly Disagree -1: Disagree 0 : Unsure 1: Agree 2: Strongly Agree

6. It is natural for people to get as much as they can in their lifetimes.

-2: Strongly Disagree -1: Disagree 0: Unsure 1: Agree 2: Strongly Agree

7. If I don't use the existing natural resources, others will, so there is no reason to conserve.

-2: Strongly Disagree -1: Disagree $\quad 0$ : Unsure 1 1: Agree 2: Strongly Agree

8. Pursuit of self-interest should be placed above other values.

-2: Strongly Disagree -1: Disagree 0: Unsure 1: Agree 2: Strongly Agree

9. The best path to true happiness is through making others happy.

-2: Strongly Disagree -1: Disagree 0: Unsure 1: Agree 2: Strongly Agree

10. People who know me well would say I'm a particularly cooperative person.

-2: Strongly Disagree -1: Disagree 0: Unsure 1: Agree 2: Strongly Agree

11. I tend to put other's needs ahead of mine.

-2: Strongly Disagree -1: Disagree 0 : Unsure 1: Agree 2: Strongly Agree

12. It's okay to drill in a wildlife reserve to obtain oil if it benefits the market. -2: Strongly Disagree -1: Disagree 0 : Unsure 1: Agree 2: Strongly Agree 
13. It is foolish to believe that what we do to the environment will have a longstanding effect.

-2: Strongly Disagree $\quad-1$ : Disagree $\quad 0$ : Unsure $\quad$ 1: Agree 2: Strongly Agree

14. I often think about how to help other people get what they want.

-2: Strongly Disagree -1: Disagree 0: Unsure 1: Agree 2: Strongly Agree

15. My financial goal is to do better than my peers.

-2: Strongly Disagree -1: Disagree 0 : Unsure 1: Agree 2: Strongly Agree

16. Conservation is not my job.

-2: Strongly Disagree -1: Disagree $\quad 0$ : Unsure $\quad 1$ : Agree 2: Strongly Agree

17. The main reason for conserving energy is to help save money.

-2: Strongly Disagree -1: Disagree 0: Unsure 1: Agree 2: Strongly Agree

18. I want to do better in life than most other people.

-2: Strongly Disagree -1: Disagree 0 : Unsure 1: Agree 2: Strongly Agree

19. Competition is the natural behavioral state of humans.

-2: Strongly Disagree -1: Disagree $\quad 0$ : Unsure 1: Agree 2: Strongly Agree

20. The environment can compensate for the pollution we create.

-2: Strongly Disagree -1: Disagree 0: Unsure 1: Agree 2: Strongly Agree

21. I should be able to use all the natural resources I want.

-2: Strongly Disagree -1: Disagree 0 : Unsure 1: Agree 2: Strongly Agree

22. Nature has a value more than money.

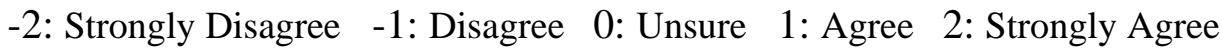

23. It is okay to use animals to test things that may benefit humankind.

-2: Strongly Disagree -1: Disagree $\quad 0$ : Unsure 1: Agree 2: Strongly Agree

24. If people really need a scarce environmental resource, they should use it.

-2: Strongly Disagree -1: Disagree $\quad 0$ : Unsure 1: Agree 2: Strongly Agree

25. I care about the environmental impact of the products I buy.

-2: Strongly Disagree -1: Disagree 0 : Unsure 1: Agree 2: Strongly Agree

26. If most people are wasting resources, then I should conserve to compensate. -2: Strongly Disagree -1: Disagree $\quad 0$ : Unsure 1: Agree 2: Strongly Agree 
27. I want to be the best at what I do.

-2: Strongly Disagree -1: Disagree 0 : Unsure 1: Agree 2: Strongly Agree

28. If people would just cooperate more, we wouldn't have so many problems in this world.

-2: Strongly Disagree - 1 : Disagree $\quad 0$ : Unsure $\quad$ 1: Agree 2: Strongly Agree

29. We should work together to achieve the things we want.

-2: Strongly Disagree -1: Disagree 0: Unsure 1: Agree 2: Strongly Agree

30. In competition, winning is not just a good thing, it's the only thing I'll accept.

-2: Strongly Disagree -1: Disagree 0: Unsure 1: Agree 2: Strongly Agree

31. I must take care of myself first and foremost.

-2: Strongly Disagree -1: Disagree 0 : Unsure 1: Agree 2: Strongly Agree

32. Conservation (of natural resources) is too inconvenient for me.

-2: Strongly Disagree -1: Disagree 0: Unsure 1: Agree 2: Strongly Agree

33. In making ecological decisions, it is important to consider the needs of humans over animals.

-2: Strongly Disagree - 1 : Disagree 0 : Unsure 1: Agree 2: Strongly Agree

34. When you play a game, it is important that your opponent have a good time. -2: Strongly Disagree -1: Disagree 0: Unsure 1: Agree 2: Strongly Agree 